\title{
A case of spontaneous mesenteric hematoma with diagnostic difficulty
}

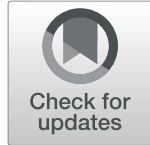

\author{
Nobuhisa Tanioka ${ }^{\text {* }^{*}}$, Hiromichi Maeda', Sachi Tsuda', Jun Iwabu', Tsutomu Namikawa', Mitsuko Iguchi ${ }^{2}$ and \\ Kazuhiro Hanazaki ${ }^{1}$
}

\begin{abstract}
Background: Spontaneous mesenteric hematoma $(\mathrm{SMH})$ is a rare condition characterized by intraperitoneal hemorrhage of unknown etiology. SMH without worsening of general status allows conservative management; however, patients showing chronological changes on imaging require surgical intervention to rule out possible malignancy.

Case presentation: A 69-year-old man was referred to our hospital to evaluate an abdominal mass with no associated clinical symptoms. He had a history of chronic hepatitis $C$ and diabetes mellitus. Six months earlier, computed tomography $(\mathrm{CT})$ revealed a $75-\mathrm{mm}$ tumor arising from the jejunum, suspected to be a gastrointestinal stromal tumor (GIST) of the small intestine. Following a further 6 months of observation, the patient was referred to our hospital. Abdominal contrast-enhanced CT revealed a well-defined heterogeneous round tumor with a maximum diameter of $75 \mathrm{~mm}$ adjacent to the upper jejunum. The tumor was accompanied by calcification at the periphery, with no evidence of augmentation over the prior 6 months. Diffuse lymphadenopathy was observed around the aorta and splenic artery. Under the diagnosis of GIST arising from small intestine, the patient underwent elective surgery. The resection revealed an elastic soft tumor at the mesentery adjacent to the upper jejunum with severe adhesion between the tumor and jejunum. The tumor origin was unclear; thus, we performed mesenteric excision and partial enterectomy without lymph node dissection.

The tumor was surrounded by fibrous capsular tissue containing massive hemosiderin deposits and cholesterol crystals showing partial calcification, resulting in a diagnosis of spontaneous hematoma of the mesentery.

Conclusions: We report a case of SMH mimicking small intestinal GIST. It is difficult to diagnose long-established $\mathrm{SMH}$ because its radiological features change with time, and more case reports are needed to improve the accuracy of diagnosis.
\end{abstract}

Keywords: Intraperitoneal hemorrhage, Mesenteric hematoma, Gastrointestinal stromal tumor, Calcification

\section{Background}

Mesenteric hematoma is a rare condition resulting from localized bleeding in peripheral mesenteric vessels that is generally caused by abdominal trauma, postoperative complications, or aneurysm [1-3]. Previous studies identified several potential risks for mesenteric hematoma including pancreatitis, vasculitis, connective tissue disease,

\footnotetext{
* Correspondence: jm-nobtanioka@kochi-u.ac.jp; nobtanioka@gmail.com 'Department of Surgery, Kochi Medical School Hospital, Kochi University, Kohasu, Oko-cho, Nankoku, Kochi 783-8505, Japan

Full list of author information is available at the end of the article
}

and anticoagulant mismanagement [4-6]. Spontaneous mesenteric hematoma ( $\mathrm{SMH})$ is generally defined as a mesenteric hematoma in the absence of these causative clinical and pathological findings.

A SMH patient present with nonspecific symptoms and diagnosis is generally made based on abdominal contrast-enhanced computed tomography (CT), ultrasound, or magnetic resonance imaging (MRI). SMH can be safely observed if the patient shows no sign of worsening general status or exacerbation of symptoms; however, the onset of diagnostic difficulty due to changes in

\section{Springer Open}

(๑) The Author(s). 2020 Open Access This article is licensed under a Creative Commons Attribution 4.0 International License, which permits use, sharing, adaptation, distribution and reproduction in any medium or format, as long as you give appropriate credit to the original author(s) and the source, provide a link to the Creative Commons licence, and indicate if changes were made. The images or other third party material in this article are included in the article's Creative Commons licence, unless indicated otherwise in a credit line to the material. If material is not included in the article's Creative Commons licence and your intended use is not permitted by statutory regulation or exceeds the permitted use, you will need to obtain permission directly from the copyright holder. To view a copy of this licence, visit http://creativecommons.org/licenses/by/4.0/. 
the imaging findings over time requires surgical resection for both diagnosis and treatment.

\section{Case presentation}

A 69-year-old man, without a remarkable family history, was referred to our hospital with an undiagnosed, asymptomatic abdominal mass. He had a history of chronic hepatitis $\mathrm{C}$ and diabetes mellitus, and generally used a proton pomp inhibiter and branched-chain amino acid formula without any anticoagulant. The patient was also a habitual drunkard. Six months earlier, his previous doctor diagnosed chronic hepatitis and detected a 75$\mathrm{mm}$ tumor arising from the jejunum by $\mathrm{CT}$ imaging (Fig. 1a). The doctor suspected the tumor to be a GIST of the small intestine. The patient was referred to our hospital 6 months following the imaging results, but he presented no characteristic clinical symptoms such as abdominal pain, nausea, and melena. Physical examination revealed a hard-palpable mass in the left upper quadrant of the abdomen, and laboratory blood testing revealed the following findings: hemoglobin, $11.0 \mathrm{~g} / \mathrm{dL}$ (normal range 13.4-17.4 g/dL); white blood cells, 1500/L (3600-9000/L); platelet count, $132 \times 100 / \mathrm{L}(138-309 \times 100 / \mathrm{L})$; albumin, $3.0 \mathrm{~g} / \mathrm{dL}(3.8-5.3 \mathrm{~g} / \mathrm{dL})$; total bilirubin, $0.9 \mathrm{mg} / \mathrm{dL}(0.2-1.2$ $\mathrm{mg} / \mathrm{dL}) ;$ aspartate transaminase (AST), $76 \mathrm{IU} / \mathrm{L}(10-35$ IU/L); alanine transaminase (ALT), $61 \mathrm{IU} / \mathrm{L}(5-46 \mathrm{IU} / \mathrm{L})$; alkaline phosphatase (ALP), 809 IU/L (115-359 IU/L); $\gamma$ glutamyl transpeptidase (GTP), $27 \mathrm{IU} / \mathrm{L}(16-73 \mathrm{IU} / \mathrm{L})$; hepatitis $\mathrm{C}$ virus (HCV) 3 antibody, $46.5 \mathrm{U}(<1.0 \mathrm{U})$; and
HCV-RNA $6.0 \log \mathrm{IU} / \mathrm{mL}(<1.2 \log \mathrm{IU} / \mathrm{mL})$. Other laboratory tests were within normal range, including a blood smear and tumor marker analysis (carcinoembryonic antigen, carbohydrate 19-9 and carbohydrate 125, soluble interleukin-2 receptor).

Abdominal contrast-enhanced CT revealed a welldefined, heterogeneous, round tumor, with a maximum diameter of $75 \mathrm{~mm}$ adjacent to the upper jejunum, with no worsening for 6 months (Fig. 1b, c). The tumor showed calcification at the periphery and there was diffuse lymphadenopathy around the aorta and splenic artery. Imaging by (18)F-fluorodeoxyglucose (FDG) positron emission tomography (PET)-CT showed slight accumulation $\left(\mathrm{SUV}_{\max } 1.5-\right.$ 2.0) of FDG around the tumor, but no sign of FDG accumulation inside the tumor (Fig. 1d). The nuclear isotope also appeared in the diffuse lymphadenopathy, but the results were difficult to differentiate from nonspecific accumulation due to chronic inflammation.

Based on the findings to this point, we diagnosed the tumor as GIST arising from jejunum and performed a laparotomy for the purpose of diagnosis and treatment. An elastic soft tumor was located at the mesentery adjacent to the upper jejunum with severe adhesion between the tumor and jejunum. The tumor origin was unclear; thus, we performed mesenteric excision and partial enterectomy without lymph node dissection.

Histological analysis of the resected tumor showed a cystic lesion surrounded by fibrous capsular tissue
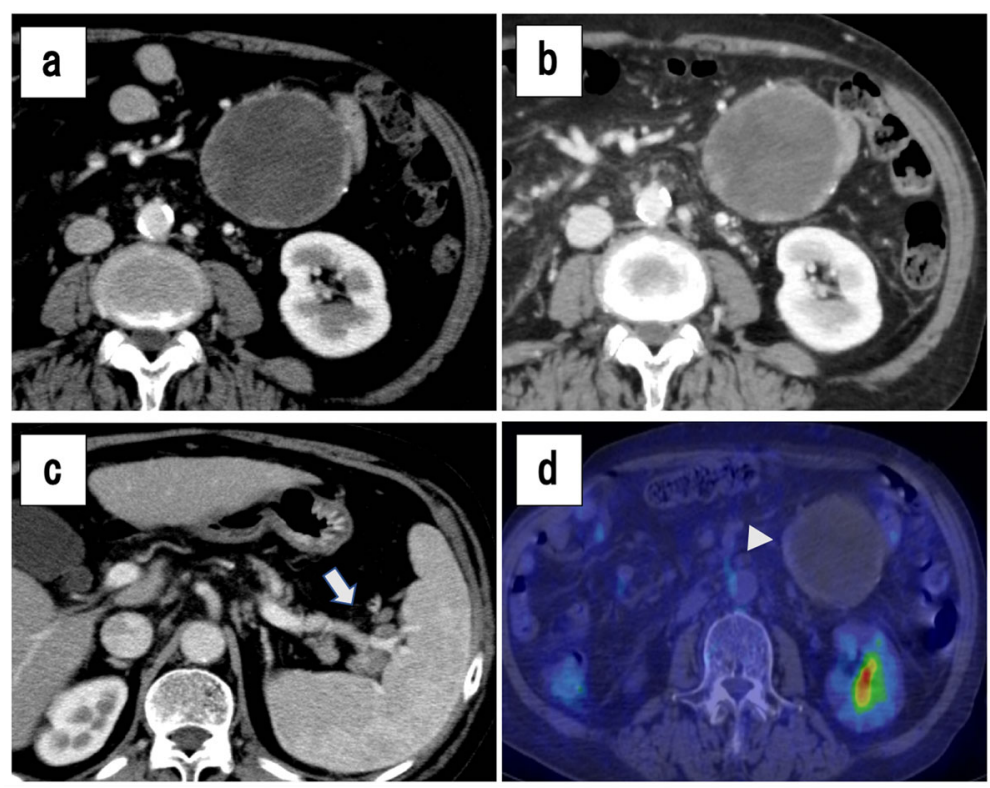

Fig. 1 Abdominal contrast-enhanced computed tomography (CT) findings (a-c). a A well-defined, mixed-density, round tumor with a maximum diameter of $77 \mathrm{~mm}$, adjacent to the upper jejunum. b The tumor was accompanied by calcification at part of the border. c Diffuse lymphadenopathy was detected at the paraaortic, splenic artery region, and splenic hilum area (arrow). d (18)F-FDG PET-CT showed slight accumulation (SUVmax 1.5-2.0) along the tumor border, corresponding to the calcified portion (arrowhead) 
containing extensive hemosiderin deposits and cholesterol crystals with partial calcification (Fig. 2a). The cystic wall contained no obvious elastic tissue, vessels, or epithelial cells, indicating that the lesion was a pseudocyst. Tumor was also located in the mesenteric fat tissue at the jejunal serosa, and there were no atypical cells in the jejunal mucosal surface (Fig. 2b). Immunohistochemistry showed negative findings for S-100, DOG-1, and 1 $\alpha$-SMA. The resected specimen also showed mesenteric hematoma, but histopathology did not reveal the source of bleeding such as aneurysm or vasculitis. There are several diseases that may cause mesenteric hematoma, such as Ehlers-Danlos syndrome, Osler-Weber-Rendu disease, polyarteritis nodosa, Behçet disease, and several bleeding diatheses. Although we did not thoroughly investigate the presence or absence of these conditions, we finally diagnosed it as $\mathrm{SMH}$ because there were no history or clinical signs suggesting of these conditions. The patient was discharged on POD 11 with no significant complications.

\section{Discussion}

$\mathrm{SMH}$ is a rare condition involving intraperitoneal hemorrhage [7]. The most common clinical symptom is abdominal pain, the severity of which depends on the location and size of the tumor $[8,9]$. Nausea or constipation may occur if the tumor is large enough to compress the digestive tract [10]. Nonspecific symptoms make it difficult to reach a diagnosis from medical interview, and SMH is usually identified by abdominal contrastenhanced CT, ultrasound, or magnetic resonance imaging (MRI) [8].

To the best of our knowledge, only 10 reported cases of SHM accompanied by comprehensive and publicly available data appear by MEDLINE searching of English literature (Table 1) [8-17], and 5 of these were reported from Asia. Together, these cases reveal two important findings; it is relatively easy to reach the diagnosis of hematoma in the early phase from onset, and aspiration biopsy should not be performed for the diagnosis. Unlike our case, the other 10 cases involved different symptoms such as abdominal pain, nausea, and diarrhea, while 6 patients had a history of sudden onset within 1 week, and 5 were initially diagnosed as hematoma based on enhanced CT or evidence of anemia progression. In 7 patients with stable general status who were observed conservatively, 1 showed no shrinkage of tumor following 60 days of observation and underwent elective surgery [12]. Another patient underwent biopsy during the observation period because malignant disease could not be excluded by initial imaging, resulting in rebleeding and emergency surgery [15]. We thus consider that tumor puncture is not recommended in any situation due to the possibility of rebleeding and peritoneal dissemination.

Takashimizu et al. [18] reviewed 20 cases of SMH published in Japanese and precisely analyzed the imaging findings. Their results suggested that the CT imaging of hematoma changes with time, and it is particularly difficult to diagnose $\mathrm{SMH}$ after a long time has passed from onset. On standard CT imaging, hematoma showed 70-90 Hounsfield Unit (HU) with high- and iso mixed-density lesions during 0-14 days from onset, 20-30 HU with high- and low mixed-density lesion during 14-28 days, and low-homogeneous lesion after 28 days. On enhanced CT imaging, hematoma showed well-defined lesion with enhanced periphery during 14-28 days, and sometimes accompanied by an enhanced septal wall like polycystic lesion after 28 days. Since malignant disease could not be excluded, 6 patients underwent surgery; these all belonged to the group of over 28
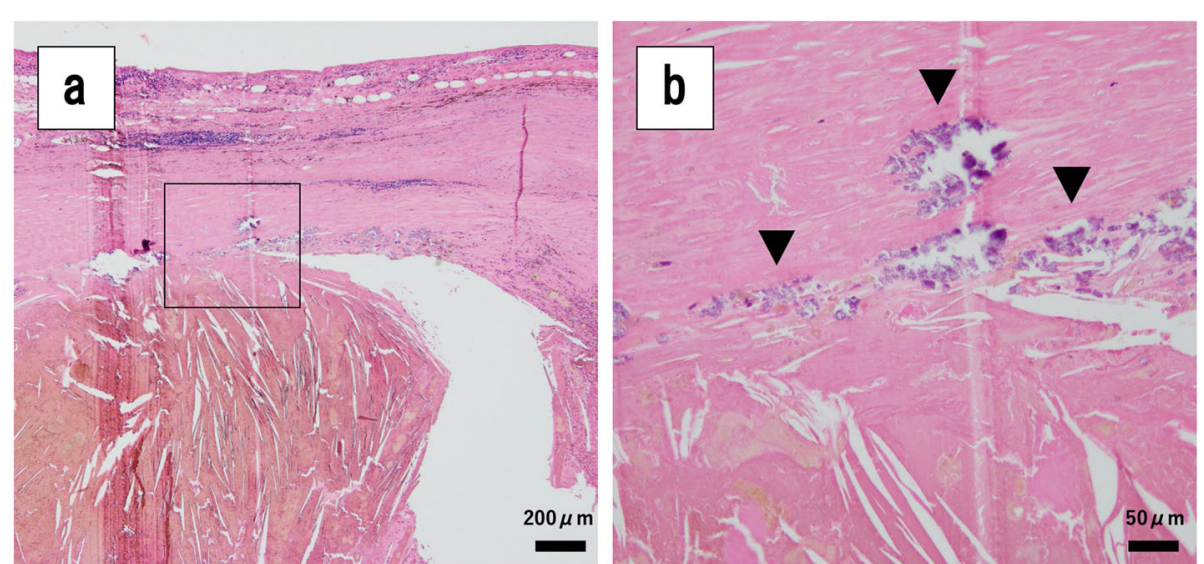

Fig. 2 Pathological findings. a, b The tumor was surrounded by a fibrous capsule, containing massive hemosiderin deposits and cholesterol crystals showing partial calcification (arrowhead). The cystic wall contained no elastic fibers, vessels, or epithelial cells, indicating it was a pseudocyst. The tumor was located in mesenteric fat tissue and in the jejunal serosa, with no atypical cells at the jejunal mucosal surface 


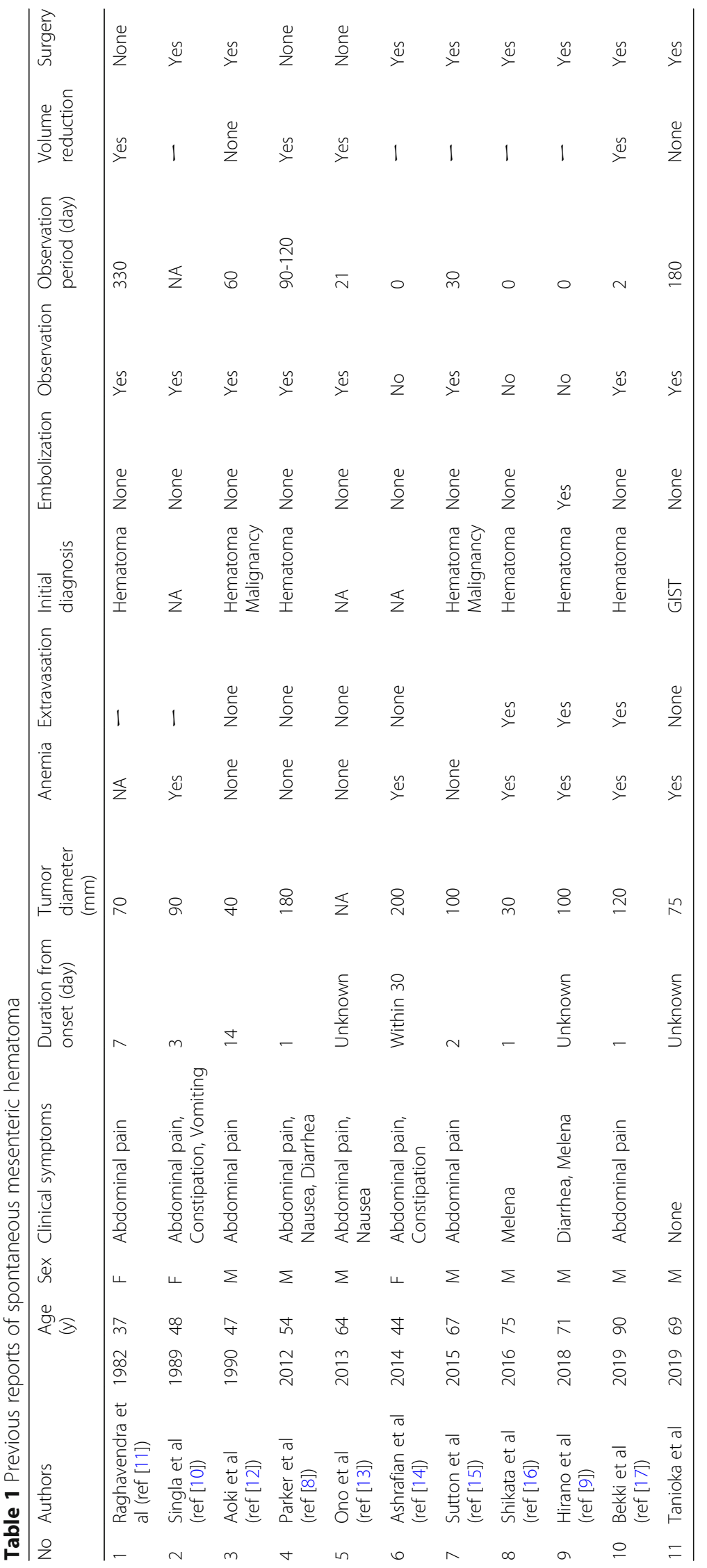


days since onset or unknown onset. This course was chosen because it is difficult to distinguish chroniccourse hematoma from abscess or other cystic tumors, particularly when it forms a polycystic appearance. It is also important to distinguish SMH from GIST of small intestine or mesenteric lymphoma due to the most common site.

In our case, the mesenteric hematoma was accompanied by an enhanced periphery with calcification, but we did not find this feature in previous reports. It is not surprising that chronic hematoma becomes calcified, since similar findings are reported regularly with long-term hemorrhage such as chronic subdural hematoma $[19,20]$; however, such a clinical picture did not rule out GIST in our patient at that time.

The usefulness of tumor calcification pattern for distinguishing SMH from small intestinal GIST remains unclear, largely because few reports have investigated the calcified hematoma with the exception of chronic subdural hematoma. Such calcification is estimated to occur in $0.3-2.7 \%$ of cases with chronic subdural hematoma, identified by high density at the lesion rim by CT [21]. On the other hand, calcified GIST is also rare $(1.5-12 \%)$ and commonly forms as nodular or focal calcifications [22, 23], which sometimes form an extensive pattern [24]. To our knowledge, no related report focuses on the pattern of calcified GIST, although while tumor accompanied by calcification from the periphery raises the possibility of hematoma, it cannot completely rule out a GIST diagnosis.

\section{Conclusion}

In summary, we described a case of SMH mimicking small intestinal GIST. It is difficult to diagnose longterm SMH because its radiological features change over time, and differ among cases. Further case reports are needed to improve the accuracy of diagnosing SMH.

\section{Abbreviations \\ SMH: Spontaneous mesenteric hematoma; GIST: Gastrointestinal stromal tumor; CT: Computed tomography; AST: Aspartate transaminase; ALT: Alanine transaminase; ALP: Alkaline phosphatase; GTP: $\gamma$-glutamyl transpeptidase; HCV: Hepatitis C virus HCV; FDG: Fluorodeoxyglucose; PET: Positron emission tomography; DOG-1: Discovered on GIST; a-SMA: a-smooth muscle actin; MRI: Magnetic resonance imaging; SUV: Standardized uptake value; HU: Hounsfield Unit}

\section{Acknowledgements}

Not applicable.

\section{Authors' contributions}

$\mathrm{MH}$ conceived and supervised the study concept. All authors participated in revising the manuscript and approved the final manuscript.

\section{Funding}

Not applicable.

\section{Availability of data and materials}

The dataset supporting the conclusions of this article is included within the article.

Ethics approval and consent to participate

Not applicable.

\section{Consent for publication}

Written informed consent was obtained from the patient for publication of this case report and accompanying images.

\section{Competing interests}

The authors declare that they have no competing interest.

\section{Author details}

${ }^{1}$ Department of Surgery, Kochi Medical School Hospital, Kochi University, Kohasu, Oko-cho, Nankoku, Kochi 783-8505, Japan. ${ }^{2}$ Department of Pathology, Kochi Medical School, Kohasu, Oko-cho, Nankoku, Kochi 783-8505, Japan.

Received: 10 October 2019 Accepted: 10 May 2020

Published online: 01 June 2020

References

1. Meissnitzer MW, Stättner S, Meissnitzer T. Small mesenteric hematoma following blunt abdominal trauma as early sign in computed tomography of occult small bowel perforation-report of 2 cases. Emerg Radiol. 2014;21: 647-50.

2. Karam KS, Hajj SN. Mesenteric hematoma--meckel's diverticulum: a rare laparoscopic complication. Fertil Steril. 1977;28:1003-5.

3. Skudder PA Jr, Craver WL. Mesenteric hematoma suggests rupture of visceral artery aneurysm. Arch Surg. 1984;119:863.

4. De Brito P, Gomez MA, Besson M, Scotto B, Alison D. Mesenteric hematoma: unusual complication of a long term oral anticoagulation therapy. Ann Chir. 2006;131:529-32 F.

5. Hosaka A, Miyata T, Shigematsu H, Deguchi JO, Kimura H, Nagawa H, Sato O, Sakimoto T, Mochizuki T. Spontaneous mesenteric hemorrhage associated with Ehlers-Danlos syndrome. J Gastrointest Surg. 2006;10:583-5.

6. Matsuo S, Yamaguchi S, Miyamoto S, Ishii T, Tsuneoka N, Obata S, Hayashi T, Kanematsu T. Ruptured aneurysm of the visceral artery: report of two cases. Surg Today. 2001;31:660-4.

7. Cawyer JC, Stone CK. Abdominal apoplexy: a case report and review. J Emerg Med. 2011;40:e49-52.

8. Parker SG, Thompson JN. Spontaneous mesenteric haematoma; diagnosis and management. BMJ Case Rep. 2012;2012.

9. Hirano K, Bando T, Osawa S, Shimizu T, Okumura T, Fujii T. Spontaneous mesenteric hematoma of the sigmoid colon associated with rivaroxaban: a case report. Int J Surg Case Rep. 2018:44:33-7.

10. Singla SK, Champakam NS, Bishnoi PK, Bajaj P, Chopra S. Spontaneous mesenteric hematoma. Indian J Gastroenterol. 1989;8:120-1.

11. Raghavendra BN, Grieco AJ, Balthazar EJ, Megibow AJ, Subramanyam BR. Diagnostic utility of sonography and computed tomography in spontaneous mesenteric hematoma. Am J Gastroenterol. 1982;77:570-3.

12. Aoki $T$, Nishizono $M$, Niina $H$, Inatsu $H$, Komidori $H$, Itano $T$, Daimon $Y$, Haraguchi Y, Yoshida T, Tanaka K. A case of spontaneous mesenteric hematoma and a review of 17 cases in Japan. Gastroenterol Jpn. 1990;25: 768-73 Review.

13. Ono H, Tasaki T, Tanahashi J, Murakami K. Spontaneous mesenteric hematoma with duodenal stenosis. Intern Med. 2013;52:1267-8.

14. Ashrafian H, Manfield JH, Mitra A, Boyle DJ, Mathur P. Spontaneous mesenteric hematoma complicating an exacerbation of Crohn's disease: report of a case. BMC Surg. 2014;14:35.

15. Sutton E, Emuakhagbon V, Jones VM, McMasters K. Spontaneous mesenteric hematoma associated with recurrent incarcerated inguinal hernia. Am Surg. 2015;81:E3-5.

16. Shikata D, Nakagomi H, Takano A, Nakagomi T, Watanabe H, Maruyama M, Nakada H, Yamamoto A, Furuya K, Hada M, Miyasaka Y, Omata M, Oyama T. Report of a case with a spontaneous mesenteric hematoma that ruptured into the small intestine. Int J Surg Case Rep. 2016;24:124-7.

17. Bekki T, Yano T, Okuda H, Egi H, Yonehara S, Amano H, Noriyuki T, Nakahara $\mathrm{M}$. A spontaneous mesenteric hematoma with a fistula between the 
transverse colon resected by laparoscopic surgery: a case report. Int J Surg Case Rep. 2019;56:20-4.

18. Takashimizu K, Kikuchi I, Sato T, Otsuka K, Sasaki K. A case of spontaneous hematoma with duodenal stenosis treated conservatively. JIMA. 2017:69:437 in Japanese.

19. Juan WS, Tai SH, Hung YC, Lee EJ. Multiple tenting techniques improve dead space obliteration in the surgical treatment for patients with giant calcified chronic subdural hematoma. Acta Neurochir. 2012;154:707-10.

20. Amr R, Maraqa L, Choudry Q. 'Armoured brain'. A case report of a calcified chronic subdural haematoma. Pediatr Neurosurg. 2008;44(1):88-9.

21. Lee BH, Hwang YJ, Choi CY. Serial CT findings of a rapidly calcified epidural hematoma in a young adult: a case report. J Neuroimaging. 2014;24:531-2.

22. Levy AD, Remotti HE, Thompson WM, Sobin LH, Miettinen M.

Gastrointestinal stromal tumors: radiologic features with pathologic correlation. Radiographics. 2003:23:283-304.

23. Inoue A, Ota S, Sato S, Nitta N, Shimizu T, Sonoda H, Tani M, Ban H, Inatomi $\mathrm{O}$, Ando A, Kushima R, Murata K. Comparison of characteristic computed tomographic findings of gastrointestinal and non-gastrointestinal stromal tumors in the small intestine. Abdom Radiol (NY). 2019:44:1237-45.

24. Salati M, Orsi G, Reggiani Bonetti L, Di Benedetto F, Longo G, Cascinu S. Heavily calcified gastrointestinal stromal tumors: pathophysiology and implications of a rare clinicopathologic entity. World J Gastrointest Oncol. 2017;9(3):135-41.

\section{Publisher's Note}

Springer Nature remains neutral with regard to jurisdictional claims in published maps and institutional affiliations.

\section{Submit your manuscript to a SpringerOpen ${ }^{\circ}$ journal and benefit from:}

- Convenient online submission

- Rigorous peer review

- Open access: articles freely available online

- High visibility within the field

- Retaining the copyright to your article

Submit your next manuscript at $\boldsymbol{\nabla}$ springeropen.com 